Article

\title{
Understanding Public Intentions to Pay for the Conservation of Urban Trees Using the Extended Theory of Planned Behavior
}

\author{
Chyi-Rong Chiou ${ }^{1}{ }^{(}$, Wei-Hsun Chan ${ }^{1,2, * \mathbb{C}}$, Jiunn-Cheng Lin $^{2}$ and Meng-Shan $\mathrm{Wu}^{2}{ }^{2}$ \\ 1 School of Forestry and Resource Conservation, National Taiwan University, Taipei 106, Taiwan; \\ esclove@ntu.edu.tw \\ 2 Taiwan Forestry Research Institute, Taipei 100, Taiwan; ljc@tfri.gov.tw (J.-C.L.); \\ wumengshan@tfri.gov.tw (M.-S.W.) \\ * Correspondence: frog@tfri.gov.tw; Tel.: +886-2-2303-9978
}

Citation: Chiou, C.-R.; Chan, W.-H.; Lin, J.-C.; Wu, M.-S. Understanding Public Intentions to Pay for the Conservation of Urban Trees Using the Extended Theory of Planned Behavior. Sustainability 2021, 13, 9228 https://doi.org/10.3390/su13169228

Academic Editor:

Giouli Mihalakakou

Received: 22 July 2021

Accepted: 15 August 2021

Published: 17 August 2021

Publisher's Note: MDPI stays neutral with regard to jurisdictional claims in published maps and institutional affiliations.

Copyright: (c) 2021 by the authors. Licensee MDPI, Basel, Switzerland. This article is an open access article distributed under the terms and conditions of the Creative Commons Attribution (CC BY) license (https:// creativecommons.org/licenses/by/ $4.0 /)$.

\begin{abstract}
Urban trees could provide a variety of ecosystem services. However, they require conservation to sustain a healthy and consistent provision of services. This study applies an extended theory of planned behavior (ETPB) to understand residents' pay intention for conserving urban trees. In order to explore the impact of the public perception of urban trees, two constructs such as perceived usefulness and perceived tree benefits have been added to the TPB model. This study conducted a questionnaire survey on Taipei city residents and received 364 valid responses. The partial least squares structural equation modeling (PLS-SEM) was used for the analysis of the model. The results show that residents' perceived usefulness and perceived tree benefits of urban trees have a significantly positive impact on public attitude toward protecting urban trees. Individuals' intention to pay towards conservation of urban trees is, on the other hand, affected by subjective norm, attitude, perceived behavioral control, and perceived usefulness. Thus, with education and promotion of tree usefulness and benefits of ecosystem services, it is helpful to improve residents attitudes regarding the protection of urban trees and increase their intention to pay for urban tree conservation.
\end{abstract}

Keywords: urban trees; ETPB; perceived usefulness; perceived tree benefits

\section{Introduction}

Urban trees are those that trees grow in urban environments, such as on the peripheries of buildings, pavements, refuge islands, or parks, and are one of the important green resources in a city [1-3]. Urban trees can provide a variety of ecosystem services, allowing residents to obtain multiple benefits, and ameliorating adverse impacts induced by artificial structures [4]. Examples include absorbing $\mathrm{CO}_{2}$ and releasing $\mathrm{O}_{2}$ [5,6], mitigation of hot temperatures [7,8], improving urban air quality [9], mitigating noise [10], increasing in wildlife habitats [11], creating educational values and recreational functions [12,13], enhancing aesthetics of urban environments as visual amenities [14], and increasing property values $[15,16]$.

However, stable and consistent provision of diverse tree benefits requires good conservation to sustain healthy urban trees $[3,17,18]$. Therefore, urban tree management divisions must put into resources like budgets to carry out various tasks conserving urban trees. In addition, given easy access to urban trees in residents' daily activities, public awareness and support is key information to ensuring the management divisions' efficient tasks of a variety of tree conservation $[19,20]$. Hence, understanding urban residents' attitudes, behavior or behavioral intentions will facilitate related future strategic planning for urban trees conservation, as well as giving direction to promotional education campaigns to solicit support from residents. This will also facilitate operations relating to urban trees conservation in urban settings. 
There have been many studies using the theory of planned behavior (TPB) developed by Ajzen [21] or using the extended theory of planned behavior (ETPB) by adding in other constructs to analyze different kinds of behaviors or behavioral intentions to conserve environmental resources. With respect to behaviors, in view that most of the actual work is not performed by any resident without qualified professionalism, related studies on resource conservation initiatives tended to conduct surveys mostly on public support, intentions to participate or to pay for the conservation, or willingness to pay (WTP), such as WTP for protecting water resources [22], pay intention for securing the entertainment benefits of an urban forest [23], WTP for protecting urban green space [24,25], support intention of urban tree programs [18] and intention to participate in protection initiatives for forested watershed areas [26].

The main purpose of this study reported here was to explore whether the residents' understanding of urban tree functions and benefits, namely perceived usefulness (PU) and perceived trees benefits (PTB), affects the pay intention for the conservation of urban trees. This study used an empirical research survey and analysis to answer the following research objectives: (1) to predict the pay intention for the conservation of urban trees with ETPB by including two additional constructs; (2) to explore the main predictors and their effects on the pay intention for the conservation of urban trees.

The remainder of this paper is organized as follows. In Section 2, a theoretical framework is presented, followed by the methodology and data in Section 3. Section 4 contains the analytical model results. Section 5 introduces some discussion of the findings and implications of this study. Section 6 summarizes the main conclusions.

\section{Theoretical Framework and Hypotheses}

\subsection{The Theory of Planned Behavior (TPB)}

The theory of planned behavior (TPB) was developed by Ajzen [21] based on the theory of reasoned action (TRA). A new construct called perceived behavior control (PBC) was supplemented with the TRA. The TPB is one of the most popular models for predicting psychological behavior and has been applied in various research fields. The conceptual model of TPB shows that subjective norms (SN), attitudes toward behavior (ATT), and perceived behavioral control (PBC) are three core constructs that influence individual behavioral intention (BI). Behavioral intention is the subjective probability that a person will engage in a given behavior and the strength of intent. Subjective norm is an individual's perception of social pressure from other individuals or groups that are important or close to him/her (like family members, friends, peers, and neighbors) [21]. Attitude refers to an individual's overall disposition/evaluation towards a target behavior [27], whereas perceived behavioral control (PBC) reflects an individual's perceived ability and ease of performing a particular behavior [21].

In the light of considerable research on environmental resource protection, it has been confirmed that those embracing support from families and companions (subjective norms), with a positive attitude (attitude) and believing in one's own ability to participate (perceived behavioral control), were positively and significantly related to behavior intention [18,22-26]. Therefore, this study hypothesized that residents' subjective norm, attitudes toward conserving urban trees, and perceived behavioral control would have a significant effect on their behavioral intention to pay to conserve urban trees.

Hypothesis 1 (H1). Subjective norm $(S N)$ is positively and significantly associated with behavioral intention to pay to conserve urban trees (BI).

Hypothesis 2 (H2). Attitude (ATT) is positively and significantly associated with behavioral intention to pay to conserve urban trees $(B I)$.

Hypothesis 3 (H3). Perceived behavioral control (PBC) is positively and significantly associated with behavioral intention to pay to conserve urban trees (BI). 


\subsection{Extended Theory of Planned Behavior (ETPB)}

TPB has been widely applied to diverse research, which helps explain the behavioral intention of surveyed individuals. Meanwhile, TPB is also relatively flexible, for Ajzen [21] has pointed out that the framework of the original theoretical model allows additions of other constructs to accommodate research needs. Even if a construct has never been used in past studies, it can still be included to study the behavioral intention of target people in surveys so that the researcher can apply the results to more diverse research objectives or fields [28,29]. Thus, in order to investigate the impact of urban residents' perception of usefulness and their understanding of benefits regarding urban trees as well as their pay intention for conserving urban trees, this study added two other constructs to the ETPB model, perceived usefulness and perceived tree benefits.

\subsubsection{Perceived Usefulness}

Perceived usefulness is the degree to which a person believes that he/she will benefit from a particular thing. In terms of urban trees, it means that they can improve residents mental and physical health $[13,30]$ by creating benefits such as relaxation, recreation, promoting living quality, and increasing property values [31,32]. There have been studies that indicate a significant correlation between perceived usefulness and an individual's behavioral intention. The higher the perceived usefulness is, the higher the behavioral intention is $[13,31,32]$. Meanwhile, perceived usefulness can be used to quantify individual attitudes toward things. There are also studies pointing out a positive relationship between perceived usefulness and attitude. In addition, attitude works as a mediator of the impact perceived usefulness has on behavioral intention [13,33-36]. This study proposes the following two hypotheses: public understanding about the perceived usefulness of urban trees will positively influence the behavioral intention to pay to conserve urban trees and positively influence the attitude toward urban tree protection.

Hypothesis 4a (H4a). Perceived usefulness (PU) is positively and significantly associated with behavioral intention to pay to conserve urban trees (BI).

Hypothesis $4 \mathbf{b} \mathbf{( H 4 b )}$. Perceived usefulness (PU) is positively and significantly associated with attitude (ATT) toward behavior.

\subsubsection{Perceived Tree Benefits}

Urban trees could provide a variety of ecosystem service benefits, such as climate benefits like the mitigation of hot temperatures [7,8] and absorbing carbon dioxide [5,6], environmental quality benefits like reducing air pollutions [9] and noise [10], educational and leisure benefits such as providing educational and cultural values, as well recreation functions [12,13], aesthetics and landscape benefits as improving cityscape and landscape [14,37], and economic benefits, for example, increasing property values [15,16]. As is seen from above, tree benefits are numerous and come in different types. Perceived tree benefits refer to how residents recognize various ecosystem service benefits mentioned above. Besides, public understanding about the benefits could vary with lifestyles in residential areas and across cultures $[4,6,20,38]$. Despite the degrees to which they perceive a range of different benefits, residents' perception is still closely correlated with their attitude [39,40], which will also affect their support of any activities related to urban trees [41,42]. Similarly, the higher the public perception of the urban tree benefits, the higher the intention to participate or support [43-45]. Therefore, regarding perceived tree benefits, the following two hypotheses are proposed by this study: the more residents acknowledge perceived tree benefits, it will positively influence not only their behavioral intention to pay to conserve urban trees but also their attitude to conserve urban trees.

Hypothesis $\mathbf{5 b} \mathbf{b} \mathbf{H} \mathbf{5 b})$. Perceived tree benefits $(P T B)$ is positively and significantly associated with behavioral intention to pay to conserve urban trees (BI). 
Hypothesis $\mathbf{5 b} \mathbf{b} \mathbf{H} \mathbf{5 b})$. Perceived tree benefits (PTB) is positively and significantly associated with attitude (ATT) toward behavior.

\subsection{Model Hypotheses}

According to the hypotheses above, the ETPB model of this study is seen in Figure 1. The oval shapes indicate the seven constructs of this study, including the original TPB models in the square frame in which are subjective norm, attitude, perceived behavioral control, and behavioral intention, as well as two expanded constructs in this study, perceived usefulness, and perceived tree benefits. The theoretical framework consists of seven paths which are the seven hypotheses to be proved: H1, H2, H3, H4a, H4b, H5a, and H5b.

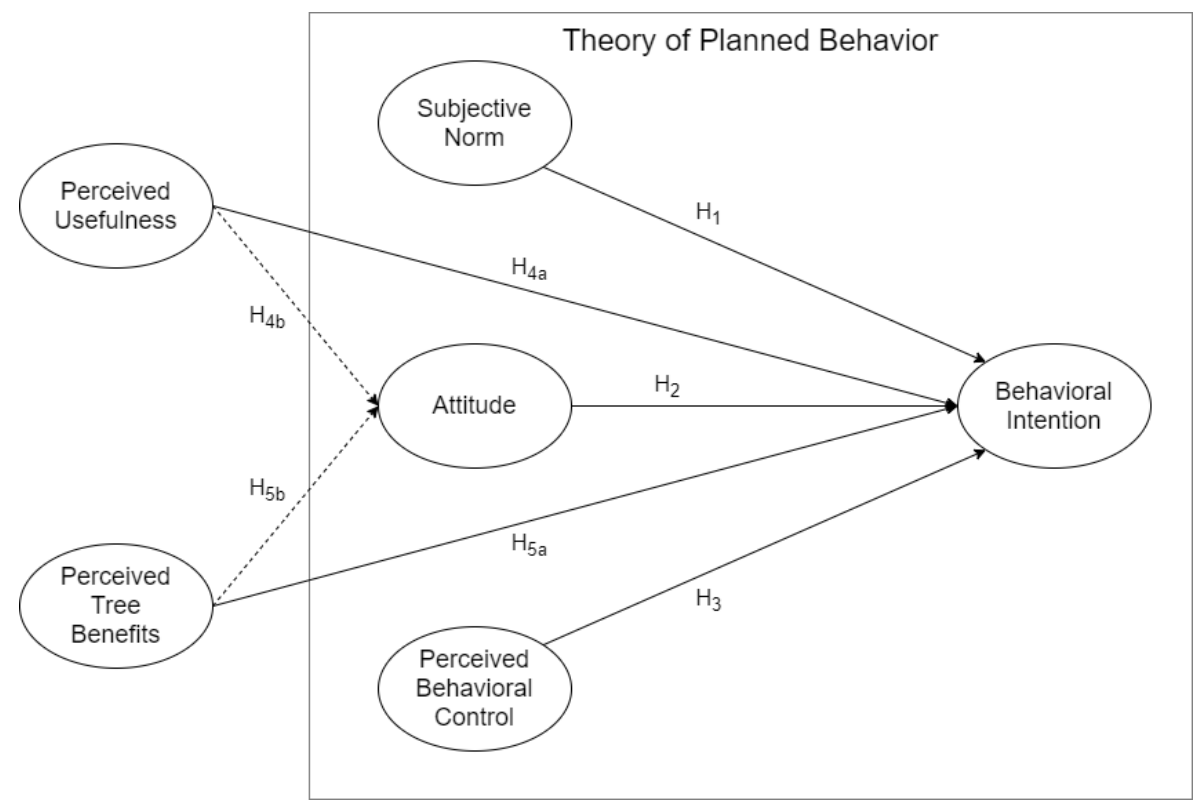

Figure 1. The research model and theoretical hypotheses. The dotted lines represented the indirect relationships.

\section{Materials and Methods}

\subsection{Questionnaire Design}

The questionnaire used for this study was mostly designed based on the TPB theoretical framework [21]. The questionnaire consisted of two parts: the first part aimed to collect the general information of respondents such as gender, age, level of education, and residential district. The second part of the questionnaire contained items for the six variables shown in Figure 1. The questions of the core constructs of the TPB (attitude, subjective norm, perceived behavioral control, and behavioral intention) were mostly adapted from previous studies $[13,21,25,46,47]$. Furthermore, the questions of the two expanded constructs (perceived usefulness and perceived tree benefits) were also designed by drawing reference to literature. The questions of the "perceived usefulness" were adapted from Balram and Dragićević [31] and Wan and Shen [46], while those of "perceived tree benefits" were adapted from Jim and Chen [6], Schroeder et al. [20], and Wan and Shen [46]. In this study, a seven-point Likert scale was used to measure the variables. The respondents expressed their agreement or disagreement for each question on a scale of 1 (strongly disagree) to 7 (strongly agree).

\subsection{Study Area and Data Collection}

Located in northern Taiwan, Taipei City $\left(25^{\circ} 2^{\prime} \mathrm{N}, 121^{\circ} 33^{\prime} \mathrm{E}\right)$ is a principal city of 12 administrative districts, covering 271.8 square kilometers and a population of 2.6 million. Within the city, there are more than 100,000 urban trees such as street trees or park trees [48] 
to which residents have easy access in their daily lives. Therefore, this study selected the Taipei city residents as the subject of interest for the survey.

There are various sample collecting methods that allow researchers to undertake random sampling when conducting surveys such as street and telephone interviews, internet questionnaires, or mail surveys [49]. Due to this fact, the surveyed individuals for this study were those who live in the urban area, contacted using mailing questionnaires for the survey. The research population was randomly sampled, aged 18-75, and with their residence registered in Taipei city. Based on the ratio of the population of Taipei city's administrative divisions [50], 3000 Taipei citizens in total were sampled for mailing questionnaire information, including descriptions about the survey, questionnaires, and self-addressed stamped envelopes with a request specifying that the respondents should mail back the questionnaires within a month.

\subsection{PLS-SEM Analysis}

This study applied PLS-SEM for analysis. The application of PLS-SEM was completed through a series of weighted regressions to optimize the structural model [51]. PLS-SEM is mainly used for prediction-oriented analyses in research [52]; moreover, it is a better statistical method to predict theory development and to explain variance in research [51]. Since this study aims to predict the behavioral intention to pay for conserving urban trees, PLS-SEM is suitable for conducting analyses.

This study used Smart PLS 3.0 software [53] to analyze data and research the evaluations of hypothetical models. There are two steps in the process. The first step is to estimate the measurement model in order to assess the reliability and validity of the measurement items statistically. The second step of analysis involves assessing the relationships and their statistical significance between various hypotheses in the structural model [54].

\subsubsection{Measurement Model}

First of all, regarding the assessment of construct reliability and validity of the measurement model, it comprises indicator reliability, composite reliability (CR), convergent validity, and discriminant validity [51]. The criteria for various indicators are as follows: (i) indicator reliability refers to that the factor loading of multiple indicators of latent constructs in the model should be greater than 0.5 [55]; (ii) the composite reliability (CR) of each latent construct should be greater than 0.6 [51]; (iii) convergent validity, the estimation of average variance extracted (AVE) of the latent construct, with a minimum threshold greater than 0.5 [56] should explain at least 50 percent of the indicators' variance, and the Cronbach's alpha value of each latent variable greater than 0.7 indicates that there is internal consistency reliability; (iv) With Fornell and Larcker's criterion to assess discriminant validity, the square root of the AVE of each latent construct in the model should be larger than the correlation coefficients of that latent construct with the other latent constructs in the model [56], which shows significant discrepancies between latent constructs.

\subsubsection{Structural Model}

When the assessment of reliability and validity of the measurement model is completed, the next step is to evaluate the structural model, including collinearity, path significance, $R$-square $\left(R^{2}\right)$, and effect size of exogenous constructs $\left(f^{2}\right)$ [51]. First of all, the collinearity of a structural model can be tested with variance inflation factors (VIF). When VIF is larger than 5, it shows that there could be latent collinearity issues in the model [57]. Path significance was determined by using a bootstrap re-sampling process, which is a nonparametric method to assess the significance level of PLS-SEM estimates by which 1000 sub-samples are generated by the responses collected by the mail survey [58]. The $R^{2}$ value is a statistical measure of the proportion of the variance explained for an endogenous construct. Where the $R^{2}$ value is $0.19-0.33$, its explanatory power is low, while a value of $0.33-0.67$ is medium-strength, and a value larger than 0.67 is high in explanatory power [54]. In addition, the main objective of the $f^{2}$ seeks to evaluate whether exogenous 
constructs have a substantive impact on the endogenous construct (i.e., the impact on $\mathrm{R}^{2}$ ). If $f^{2}$ is $0.02-0.15$, it is considered a small effect size, while a medium effect size ranges $0.15-0.35$ and a large effect size is greater than 0.35 [59].

\section{Results}

\subsection{Respondent Characteristics}

This study received 380 questionnaire responses. The response rate is about $12.6 \%$. According to a previous study conducted in Taiwan [60], the response rate of the mail survey was also about $10 \%$, so the response rate of this study is reasonable. By excluding 16 incomplete ones, there were 364 valid responses in total. The valid survey response rate is around $95.8 \%$. The minimum sample size for the partial least square (PLS) analysis should be 10 times greater than the maximum number of the hypothetical model links pointing at a particular dependent variable [61]. The hypothetical number of links directed to a dependent variable is 7 (Figure 1), so the smallest sample size should be greater than 70. Meanwhile, G*Power 3.1 software [62] allows an analysis of the sample size required for the statistical hypothesis testing using the level of significance $(\alpha)$, effect size of statistical power $\left(f^{2}\right)$, and the maximum number of predictors (np) directed to a dependent variable $[59,62,63]$. The minimum sample size required by this study is 153 $\left(\alpha=0.05 ; f^{2}=0.15 ; \mathrm{np}=7\right)$, among which an effect size of 0.15 means that a medium-level relationship strength would be detected by the statistical analysis [59]. This effect size is often used for estimating the number of samples for analysis [32,46,63]. Therefore, the 364 valid samples acquired by this survey justified the minimum sample size sufficiency.

The profile of respondents and that of the corresponding population are presented in Table 1. Most of the respondents were female $(55.8 \%)$ aged 35-44 (23.9\%) with postsecondary education $(78.9 \%)$, most of whom were those who live in Da'an administrative district $(13.8 \%)$. Using the Chi-square test to analyze the survey samples and the population profile of Taipei city [50], the sample profile in this study was generally similar to the population profile in Taipei city in terms of gender, ages, and residential districts; however, the secondary education level group was under-represented.

\subsection{PLS-SEM Analysis}

\subsubsection{Measurement Model}

Table 2 showed the results of the measurement model. First, the factor loading of each measurement indicator ranging between 0.66 and 0.95 , was higher than that suggested 0.5 by Hulland [55]. The lowest CR value of each latent variable was 0.89 (PBC and PTB), which was also higher than the suggested value of 0.6 by Hair et al. [51]. In terms of the lowest value of AVE, 0.64 (PTB), it was higher than the suggested threshold value 0.6 by Fornell and Larcker [56]. Meanwhile, the Cronbach's alpha of each latent variable was higher than 0.8 , which means there was internal consistency reliability among all items [64]. The results of discriminant validity analysis can be referred to in Table 3. The AVE square roots of all latent variables are larger than correlation coefficients of other latent variables in the model. Overall, the construct reliability and validity of each measurement model meet the requirements of assessment.

\subsubsection{Structural Model}

After the evaluation of the measurement model, the structural model should be evaluated. The bootstrap re-sampling method was used to obtain 1000 sub-samples from the original sample size of 364 gathered by this study. The analytical results of coefficients and significances of the structural model are seen in Figure 2 and Table 4 . First, the value of VIF of each construct in the model was smaller than 5 , which indicates there was no problem with collinearity for each construct. In addition, with respect to the two endogenous variables, Attitude $\left(R^{2}=0.44\right)$ and behavioral intention $\left(R^{2}=0.70\right)$, the model was equipped with medium and high explanatory power respectively, which allowed exploring the results of various parameters, significances, and hypotheses of the model. 
Table 1. Respondent profile $(\mathrm{N}=364)$.

\begin{tabular}{|c|c|c|c|c|}
\hline Demographic Variable & Sample (N) & Sample (\%) & Population (\%) & Difference (\%) \\
\hline \multicolumn{5}{|l|}{ Gender $\left(\chi^{2}=1.21 p>0.05\right)$} \\
\hline Male & 161 & 44.2 & 47.1 & -2.9 \\
\hline Female & 203 & 55.8 & 52.9 & 2.9 \\
\hline \multicolumn{5}{|l|}{ Age $\left(\chi^{2}=1.46 p>0.05\right)$} \\
\hline $18-24$ & 21 & 5.8 & 7.2 & -1.4 \\
\hline $25-34$ & 59 & 16.2 & 16.6 & -0.4 \\
\hline $35-44$ & 87 & 23.9 & 22.6 & 1.3 \\
\hline $45-54$ & 75 & 20.6 & 19.9 & 0.7 \\
\hline $55-64$ & 73 & 20.0 & 19.8 & 0.2 \\
\hline$\geq 65$ & 49 & 13.5 & 13.9 & -0.4 \\
\hline \multicolumn{5}{|c|}{ Education Level $\left(\chi^{2}=12.87 p<0.05\right)$} \\
\hline Primary & 7 & 1.9 & 1.9 & 0.0 \\
\hline Secondary & 70 & 19.2 & 26.7 & -7.5 \\
\hline Post-secondary & 287 & 78.9 & 71.4 & 7.5 \\
\hline \multicolumn{5}{|c|}{ Residential district $\left(\chi^{2}=9.90 p>0.05\right)$} \\
\hline Shilin District & 36 & 9.9 & 10.7 & -0.8 \\
\hline Datong District & 18 & 5.0 & 4.8 & 0.2 \\
\hline Da'an District & 50 & 13.8 & 11.6 & 2.2 \\
\hline Zhongshan District & 26 & 7.1 & 8.6 & -1.5 \\
\hline Zhongzheng District & 25 & 6.9 & 6.0 & 0.9 \\
\hline Neihu District & 45 & 12.4 & 10.8 & 1.6 \\
\hline Wenshan District & 34 & 9.3 & 10.3 & -1 \\
\hline Beitou District & 22 & 6.0 & 9.6 & -3.6 \\
\hline Songshan District & 32 & 8.8 & 7.7 & 1.1 \\
\hline Xinyi District & 30 & 8.2 & 8.4 & -0.2 \\
\hline Nangang District & 19 & 5.2 & 4.6 & 0.6 \\
\hline Wanhua District & 27 & 7.4 & 7.1 & 0.3 \\
\hline
\end{tabular}

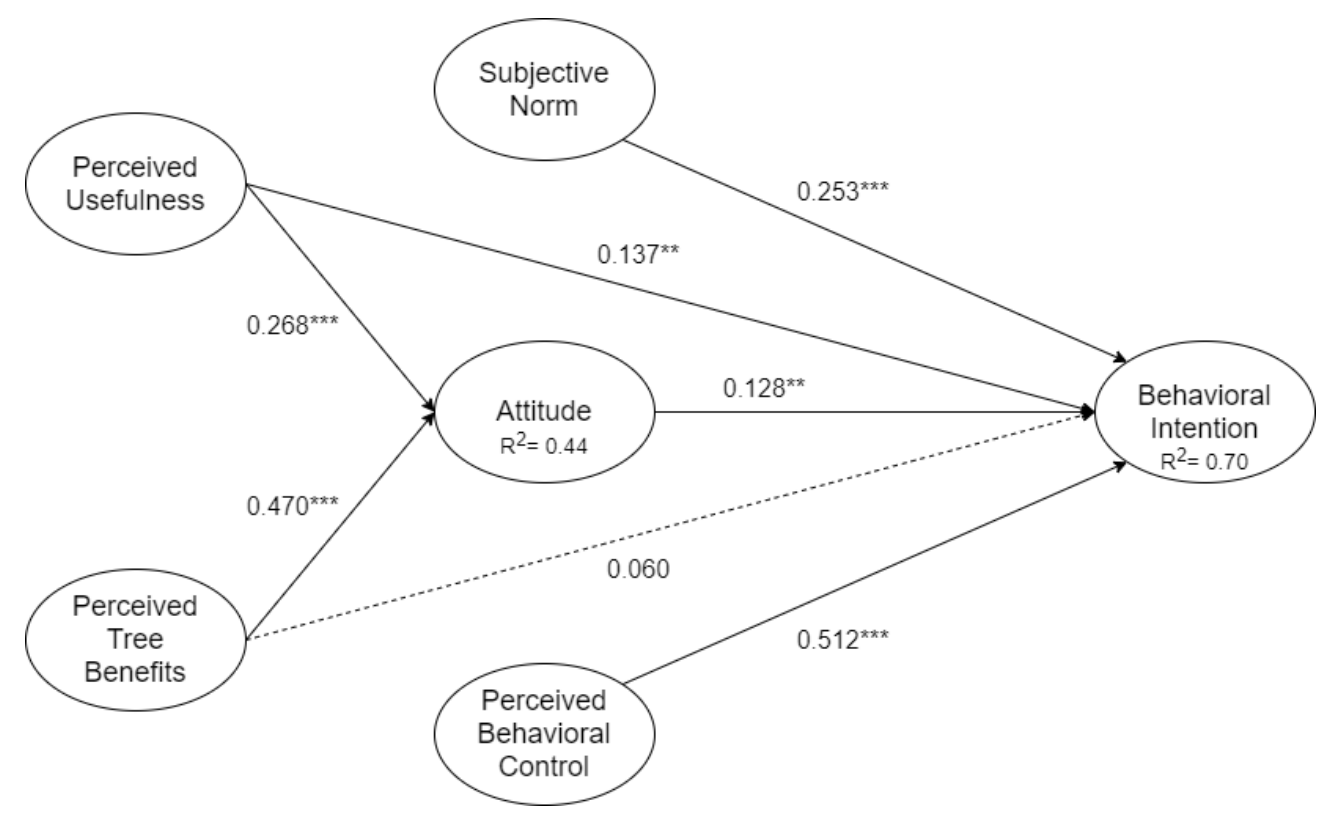

Figure 2. Path coefficient of structural model. The dotted line indicates non-significance. $\left(* * p<0.01 ;{ }^{* *} p<0.001\right)$. 
Table 2. Results of the measurement model.

\begin{tabular}{|c|c|c|c|c|c|}
\hline \multicolumn{2}{|r|}{ Indicators } & \multirow[t]{2}{*}{ Mean (SD) } & \multirow[t]{2}{*}{ FL } & \multirow{2}{*}{$\begin{array}{c}\text { AVE } \\
0.95\end{array}$} & \multirow{2}{*}{$\begin{array}{c}\text { CR } \\
0.79\end{array}$} \\
\hline Attitu & $\alpha=0.93)$ & & & & \\
\hline ATT1 & Conserving urban trees is very necessary. & $6.36(0.94)$ & 0.87 & & \\
\hline ATT2 & Conserving urban trees is very useful. & $6.35(0.91)$ & 0.91 & & \\
\hline ATT3 & Conserving urban trees is very ecological. & $6.22(1.01)$ & 0.89 & & \\
\hline ATT4 & Conserving urban trees is very positive. & $6.34(0.91)$ & 0.92 & & \\
\hline ATT5 & Conserving urban trees can improve the urban trees benefits. & $6.03(1.07)$ & 0.84 & & \\
\hline \multicolumn{2}{|c|}{ Subjective Norm $(\alpha=0.96)$} & & & 0.97 & 0.91 \\
\hline SN1 & My family think I should pay for conservation. & $4.80(1.56)$ & 0.94 & & \\
\hline SN2 & People who are important to me think I should pay for conservation. & $4.85(1.55)$ & 0.95 & & \\
\hline SN3 & The people whose opinions I value would pay for conservation. & $4.84(1.56)$ & 0.95 & & \\
\hline \multicolumn{2}{|c|}{ Perceived Behavioral Control $(\alpha=0.82)$} & & & 0.89 & 0.73 \\
\hline PBC1 & I have the resources (time or money, etc.) to pay for urban trees & $4.05(1.67)$ & 0.84 & & \\
\hline PBC2 & If I want to, I can pay to conserve urban trees. & $4.79(1.62)$ & 0.88 & & \\
\hline PBC3 & I think it's easy for me to pay to conserve the urban trees & $3.75(1.55)$ & 0.84 & & \\
\hline \multicolumn{2}{|c|}{ Perceived Usefulness $(\alpha=0.86)$} & & & 0.90 & 0.70 \\
\hline PU1 & I use places with urban trees to relax. & $5.61(1.46)$ & 0.88 & & \\
\hline PU2 & I use places with urban trees for recreation. & $5.65(1.43)$ & 0.87 & & \\
\hline PU3 & Urban trees can improve the quality of my living environment. & $5.95(1.19)$ & 0.87 & & \\
\hline PU4 & Urban trees would increase my property value. & $5.19(1.51)$ & 0.69 & & \\
\hline \multicolumn{2}{|c|}{ Perceived Tree Benefits $(\alpha=0.86)$} & & & 0.89 & 0.64 \\
\hline PTB1 & Urban trees could provide climate benefits. & $6.51(0.85)$ & 0.81 & & \\
\hline PTB2 & Urban trees could provide environmental quality benefits. & $6.41(0.93)$ & 0.82 & & \\
\hline PTB3 & Urban trees could provide educational and leisure benefits. & $6.15(1.04)$ & 0.86 & & \\
\hline PTB4 & Urban trees could provide aesthetics and landscape benefits. & $5.92(1.18)$ & 0.80 & & \\
\hline PTB5 & Urban trees could provide economic benefits. & $5.09(1.56)$ & 0.66 & & \\
\hline \multicolumn{2}{|c|}{ Behavior Intention $(\alpha=0.86)$} & & & 0.90 & 0.70 \\
\hline BI1 & I will pay to conserve urban trees if I have an opportunity. & $4.62(1.59)$ & 0.89 & & \\
\hline BI2 & I support to pay to conserve urban trees. & $5.74(1.32)$ & 0.70 & & \\
\hline $\mathrm{BI} 3$ & I intend to pay to conserve urban trees in the future. & $4.28(1.58)$ & 0.89 & & \\
\hline BI4 & I will encourage others to pay to conserve urban trees. & $4.87(1.56)$ & 0.85 & & \\
\hline
\end{tabular}

Note: $\alpha=$ Cronbach's $\alpha$ reliability, $\mathrm{SD}=$ standard deviation, $\mathrm{FL}=$ factor loading, $\mathrm{AVE}=$ average variance extracted, $\mathrm{CR}=$ composite reliability.

Table 3. Correlations among constructs. Fornell-Larcker criterion for discriminant validity.

\begin{tabular}{ccccccc}
\hline Constructs & ATT & SN & PBC & PU & PTB & BI \\
\hline ATT & 0.89 & & & & & \\
SN & 0.32 & 0.96 & & & & \\
PBC & 0.22 & 0.55 & 0.86 & & & \\
PU & 0.55 & 0.42 & 0.44 & 0.84 & 0.80 & \\
PTB & 0.63 & 0.28 & 0.21 & 0.59 & 0.40 & 0.84 \\
BI & 0.43 & 0.65 & 0.75 & 0.57 & 0.40 \\
\hline
\end{tabular}

Table 4. Testing results of the structural model path coefficients.

\begin{tabular}{|c|c|c|c|c|c|c|c|c|c|c|}
\hline \multirow{2}{*}{\multicolumn{2}{|c|}{ Hypotheses }} & \multirow{3}{*}{$\begin{array}{c}\mathbf{M} \\
0.254\end{array}$} & \multirow{3}{*}{$\begin{array}{c}\text { SD } \\
0.054\end{array}$} & \multirow{3}{*}{$\begin{array}{c}t \text {-Value } \\
4.666^{* * *}\end{array}$} & \multirow{3}{*}{$\begin{array}{c}\text { VIF } \\
1.548\end{array}$} & \multirow{3}{*}{$\begin{array}{c}f^{2} \\
0.140\end{array}$} & \multicolumn{3}{|c|}{ Effects } & \multirow{3}{*}{$\begin{array}{l}\text { Inference } \\
\text { Supported }\end{array}$} \\
\hline & & & & & & & \multirow{2}{*}{$\begin{array}{c}\text { Direct }(\boldsymbol{\beta}) \\
0.253\end{array}$} & \multirow{2}{*}{ Ind. } & \multirow{2}{*}{$\begin{array}{l}\text { Total } \\
0.253\end{array}$} & \\
\hline $\mathrm{H} 1$ & $\mathrm{SN} \rightarrow \mathrm{BI}$ & & & & & & & & & \\
\hline $\mathrm{H} 2$ & $\mathrm{ATT} \rightarrow \mathrm{BI}$ & 0.126 & 0.046 & $2.787^{* *}$ & 1.818 & 0.030 & 0.128 & & 0.128 & Supported \\
\hline H3 & $\mathrm{PBC} \rightarrow \mathrm{BI}$ & 0.513 & 0.046 & $11.215^{* * *}$ & 1.558 & 0.573 & 0.512 & & 0.512 & Supported \\
\hline $\mathrm{H} 4 \mathrm{a}$ & $\mathrm{PU} \rightarrow \mathrm{BI}$ & 0.138 & 0.044 & $3.094^{* *}$ & 1.981 & 0.032 & 0.137 & 0.034 & 0.171 & Supported \\
\hline $\mathrm{H} 4 \mathrm{~b}$ & $\mathrm{PU} \rightarrow \mathrm{ATT}$ & 0.267 & 0.060 & $4.497^{* * *}$ & 1.537 & 0.084 & 0.268 & & 0.268 & Supported \\
\hline H5a & $\mathrm{PTB} \rightarrow \mathrm{BI}$ & 0.058 & 0.036 & 1.648 & 1.942 & 0.006 & 0.060 & 0.060 & 0.120 & Not supported \\
\hline $\mathrm{H} 5 \mathrm{~b}$ & $\mathrm{PTB} \rightarrow \mathrm{ATT}$ & 0.472 & 0.059 & $7.913^{* * *}$ & 1.537 & 0.258 & 0.470 & & 0.470 & Supported \\
\hline
\end{tabular}

Note: $\mathrm{M}=$ sample mean, $\mathrm{SD}=$ standard deviation, $\mathrm{VIF}=$ variance inflation factor, ${ }^{* *} t$-value is sig. at $p<0.01,{ }^{* * *} t$-value is sig. at $p<0.001$, $\beta=$ path coefficients (direct effect). 
The three core constructs of TPB (subjective norm, attitude, and perceived behavioral control) all had significant and positive impacts on behavioral intention, among which the total effect of subjective norm was $0.253\left(\beta_{\mathrm{SN} \rightarrow \mathrm{BI}}=0.253, t=4.666, f^{2}=0.140, p<0.001\right)$, that of attitude was $0.128\left(\beta_{\mathrm{ATT}} \rightarrow \mathrm{BI}=0.128, t=2.787, f^{2}=0.030, p<0.01\right)$, and that of perceived behavioral control was $0.512\left(\beta_{\mathrm{PBC} \rightarrow \mathrm{BI}}=0.512, t=11.215, f^{2}=0.573, p<0.001\right)$. Hence the three hypotheses H1, H2, and H3 could be established. Furthermore, in terms of impact on behavioral intention, there were two expanded constructs (perceived usefulness and perceived tree benefits) added to this study, but only perceived usefulness showed a significant positive influence and its total effect was $0.171\left(\beta_{\mathrm{PU} \rightarrow \mathrm{BI}}=0.137, t=3.094\right.$, $\left.f^{2}=0.032, p<0.01\right)$. On the other hand, the impact of perceived tree benefits was not statistically notable. Thus, hypothesis H4a was established, but hypothesis H5a was turned down. Meanwhile, both the two expanded constructs affected attitude positively and significantly, of which the total effect of perceived usefulness was $0.268\left(\beta_{\mathrm{PU}} \rightarrow\right.$ ATT $=0.268, t=4.497$, $\left.f^{2}=0.084, p<0.001\right)$. As a result, both hypotheses $\mathrm{H} 4 \mathrm{~b}$ and $\mathrm{H} 5 \mathrm{~b}$ could be established.

\section{Discussion}

The results of this research model are consistent with the TPB theory proposed by Ajzen [21] and with other research results of TPB applications in different fields [13,46,65-67]. That is, the three core constructs, subjective norm, attitude, and perceived behavioral control, will significantly affect behavioral intention. As for the two expanded constructs added to this study, perceived usefulness has a remarkable impact on both attitude and behavioral intention, while perceived tree benefits also notably affect attitude. This result corresponds to that of past related studies on how perceived usefulness $[13,31-33,36]$ and perceived tree benefits $[39,40]$ influence attitude and behavioral intention. However, the impact of perceived tree benefits have on behavioral intention is not obvious, which is different from some other research results [43-45]. On the other hand, there are former research findings featuring urban green space suggesting that the relationship between public understanding of ecosystem service benefits and behavioral intention is not significant [46]. One possible explanation for this is that most urban green space is small in size or the tree coverage is more sparse and scattered; therefore, the ecosystem service benefits such as reducing noise or air pollution are less noteworthy than what a huge forest could offer [68]. In addition, urban residents' higher demands for urban trees and green space [69] result in an insignificant relationship between their understanding of ecosystem services provided by trees and their behavioral intention to pay for urban tree conservation.

As to the impact of exogenous constructs on the endogenous constructs in this study model, firstly, of all the constructs, perceived tree benefits affect attitude significantly and has a medium effect size of impact $\left(f^{2}=0.258\right)$, while the impact of perceived usefulness is considered a small effect size $\left(f^{2}=0.084\right)$, which means public understanding about the ecosystem service benefits from urban trees has a greater impact on the attitude to protect urban trees. Regarding the construct in which behavior intention has a significant impact, perceived behavioral control has a large effect size of impact $\left(f^{2}=0.573\right)$ while the other three constructs represent small effect sizes of impact: subjective norm $\left(f^{2}=0.140\right)$, perceived usefulness $\left(f^{2}=0.032\right)$, and attitude $\left(f^{2}=0.030\right)$, listed from top to bottom. That is, the pay intention for conserving urban trees is influenced the most by residents' belief in their financial resources or capability, secondly by people of importance around them, and lastly by both understanding about urban tree usefulness and attitude to protect urban trees. Former studies point out that perceived behavioral control is the main factor that affects behavioral intention (Wan and Shen, 2015; Zhao et al., 2018). There is also other research suggesting attitude has a relatively small impact on behavioral intention [33,70]. Yet, even if the influence of a construct on the model is smaller, it does not mean the influence from that construct is not important [71].

According to the results of this study, if an urban tree management division expects to promote residents' intention to pay for conservation expenses of urban trees, it is recommended to start with enhancing their perception about urban tree usefulness and 
benefits. Lo and Jim [68] have pointed out that, in general, urban residents value more of the recreational functions of urban trees and green spaces while paying less attention to their environment and social functions. In light of this, the following things can be done to promote residents' attitude and WTP to protect urban trees so that the individuals can further influence people around them (which means other people will be affected by subjective norms) to conserve urban trees in the best interests of society as a whole: encouraging residents to enjoy leisure activities where they gain exposures to urban trees, promoting education on how urban trees could benefit individuals' wellbeing and improve the environment, and informing the residents of the ecosystem services benefits urban trees could provide.

\section{Conclusions}

Urban trees are one of the important green resources in cities to deliver multiple benefits and to enhance the wellbeing of residents. However, to bring tree benefits into full play requires carrying out continuous and proper conservation tasks. This study applies the ETPB model with an addition of two constructs regarding urban tree perception: perceived usefulness and perceived tree benefits, to investigate how the constructs affect residents' behavioral intention to pay to conserve urban trees. The results show that residents' perceived usefulness and perceived benefits regarding urban trees perception positively affect their attitude to conserve urban trees. In addition, perceived usefulness and the three core concepts of TPB, which are subjective norm, attitude, perceived behavioral control, positively influence the behavioral intention to pay to conserve urban trees, which proves that residents' perceptions of urban trees have an impact on their behavioral intention. This will facilitate future strategic planning for tree conservation, as well as giving direction to promotional education campaigns to solicit support from residents.

Author Contributions: Conceptualization, W.-H.C. and C.-R.C.; methodology, J.-C.L. and C.-R.C.; data curation, M.-S.W.; writing-original draft preparation, W.-H.C.; writing-review and editing, J.-C.L.; project administration, C.-R.C. All authors have read and agreed to the published version of the manuscript.

Funding: This research was funded by the Taiwan Forestry Research Institute under grant 108AS10.3.1-FI-G1.

Institutional Review Board Statement: Not applicable.

Informed Consent Statement: Informed consent was obtained from all subjects involved in the study.

Data Availability Statement: The data presented in this study are available on request from the corresponding author.

Conflicts of Interest: The authors declare no conflict of interest.

\section{References}

1. Nowak, D.J.; Dwyer, J.F. Understanding the Benefits and Costs of Urban Forest Ecosystems. In Urban and Community Forestry in the Northeast; Springer: Dordrecht, The Netherlands, 2007; pp. 25-46.

2. Ponce-Donoso, M.; Vallejos-Barra, O.; Escobedo, F.J. Appraisal of Urban Trees Using Twelve Valuation Formulas and Two Appraiser Groups. Arboric. Urban For. 2017, 43, 72-82.

3. Roy, S.; Byrne, J.; Pickering, C. A Systematic Quantitative Review of Urban Tree Benefits, Costs, and Assessment Methods across Cities in Different Climatic Zones. Urban For. Urban Green. 2012, 11, 351-363. [CrossRef]

4. Avolio, M.L.; Pataki, D.E.; Pincetl, S.; Gillespie, T.W.; Jenerette, G.D.; McCarthy, H.R. Understanding Preferences for Tree Attributes: The Relative Effects of Socio-Economic and Local Environmental Factors. Urban Ecosyst. 2014, 18, 73-86. [CrossRef]

5. Cohen, P.; Potchter, O.; Schnell, I. The Impact of an Urban Park on Air Pollution and Noise Levels in the Mediterranean City of Tel-Aviv, Israel. Environ. Pollut. 2014, 195, 73-83. [CrossRef]

6. Jim, C.Y.; Chen, W.Y. Perception and Attitude of Residents toward Urban Green Spaces in Guangzhou (China). Environ. Manag. 2006, 38, 338-349. [CrossRef]

7. Tan, Z.; Lau, K.K.-L.; Ng, E. Urban Tree Design Approaches for Mitigating Daytime Urban Heat Island Effects in a High-Density Urban Environment. Energy Build. 2016, 114, 265-274. [CrossRef] 
8. Bowler, D.E.; Buyung-Ali, L.; Knight, T.M.; Pullin, A.S. Urban Greening to Cool Towns and Cities: A Systematic Review of the Empirical Evidence. Landsc. Urban Plan. 2010, 97, 147-155. [CrossRef]

9. Jim, C.Y.; Chen, W.Y. Assessing the Ecosystem Service of Air Pollutant Removal by Urban Trees in Guangzhou (China). J. Environ. Manag. 2008, 88, 665-676. [CrossRef] [PubMed]

10. Madureira, H.; Nunes, F.; Oliveira, J.V.; Cormier, L.; Madureira, T. Urban Residents' Beliefs Concerning Green Space Benefits in Four Cities in France and Portugal. Urban For. Urban Green. 2015, 14, 56-64. [CrossRef]

11. Chiquet, C.; Dover, J.W.; Mitchell, P. Birds and the Urban Environment: The Value of Green Walls. Urban Ecosyst. 2012, 16, 453-462. [CrossRef]

12. Tu, G.; Abildtrup, J.; Garcia, S. Preferences for Urban Green Spaces and Peri-Urban Forests: An Analysis of Stated Residential Choices. Landsc. Urban Plan. 2016, 148, 120-131. [CrossRef]

13. Yen, Y.; Wang, Z.; Shi, Y.; Xu, F.; Soeung, B.; Sohail, M.T.; Rubakula, G.; Juma, S.A. The Predictors of the Behavioral Intention to the Use of Urban Green Spaces: The Perspectives of Young Residents in Phnom Penh, Cambodia. Habitat Int. 2017, 64, 98-108. [CrossRef]

14. Seburanga, J.L.; Kaplin, B.A.; Zhang, Q.-X.; Gatesirea, T. Amenity Trees and Green Space Structure in Urban Settlements of Kigali, Rwanda. Urban For. Urban Green. 2014, 13, 84-93. [CrossRef]

15. Jim, C.Y.; Chen, W.Y. Impacts of Urban Environmental Elements on Residential Housing Prices in Guangzhou (China). Landsc. Urban Plan. 2006, 78, 422-434. [CrossRef]

16. Lin, I.H.; Wu, C.; De Sousa, C. Examining the Economic Impact of Park Facilities on Neighboring Residential Property Values. Appl. Geogr. 2013, 45, 322-331. [CrossRef]

17. Dwyer, J.F.; McPherson, E.G.; Schroeder, H.W.; Rowntree, R.A. Assessing the Benefits and Costs of the Urban Forest. J. Arboric. 1992, 18, 227-234.

18. Zhao, Z.; Zhang, Y.; Wen, Y. Residents' Support Intentions and Behaviors Regarding Urban Trees Programs: A Structural Equation Modeling-Multi Group Analysis. Sustainability 2018, 10, 377. [CrossRef]

19. Gorman, J. Residents' Opinions on the Value of Street Trees Depending on Tree Location. J. Arboric. 2004, 30, 36-44.

20. Schroeder, H.; Flannigan, J.; Coles, R. Residents' Attitudes toward Street Trees in the UK and U.S. Communities. Arboric. Urban For. 2006, 32, 236-246.

21. Ajzen, I. The Theory of Planned Behavior. Organ. Behav. Hum. Decis. Process. 1991, 50, 179-211. [CrossRef]

22. Cooper, P.; Poe, G.L.; Bateman, I.J. The Structure of Motivation for Contingent Values: A Case Study of Lake Water Quality Improvement. Ecol. Econ. 2004, 50, 69-82. [CrossRef]

23. Bernath, K.; Roschewitz, A. Recreational Benefits of Urban Forests: Explaining Visitors' Willingness to Pay in the Context of the Theory of Planned Behavior. J. Environ. Manag. 2008, 89, 155-166. [CrossRef] [PubMed]

24. Lo, A.Y.; Jim, C. Willingness of Residents to Pay and Motives for Conservation of Urban Green Spaces In the Compact City of Hong Kong. Urban For. Urban Green. 2010, 9, 113-120. [CrossRef]

25. López-Mosquera, N.; García, T.; Barrena, R. An Extension of the Theory of Planned Behavior to Predict Willingness to Pay for the Conservation of an Urban Park. J. Environ. Manag. 2014, 135, 91-99. [CrossRef]

26. Empidi, A.; Emang, D. Understanding Public Intentions to Participate in Protection Initiatives for Forested Watershed Areas Using the Theory of Planned Behavior: A Case Study of Cameron Highlands in Pahang, Malaysia. Sustainability 2021, 13, 4399. [CrossRef]

27. Ajzen, I.; Madden, T.J. Prediction of Goal Directed Behavior: Attitudes, Intentions, and Perceived Behavioral Control. J. Exp. Soc. Psychol. 1986, 22, 453-474. [CrossRef]

28. Greaves, M.; Zibarras, L.D.; Stride, C. Using the Theory of Planned Behavior to Explore Environmental Behavioral Intentions in the Workplace. J. Environ. Psychol. 2013, 34, 109-120. [CrossRef]

29. Wang, D.; Brown, G.; Liu, Y.; Mateo-Babiano, I. A Comparison of Perceived and Geographic Access to Predict Urban Park Use. Cities 2015, 42, 85-96. [CrossRef]

30. Davis, F.D. Perceived Usefulness, Perceived Ease of Use, and User Acceptance of Information Technology. Manag. Inf. Syst. Q. 1989, 13, 319-340. [CrossRef]

31. Balram, S.; Dragievi, S. Attitudes toward Urban Green Spaces: Integrating Questionnaire Survey and Collaborative GIS Techniques to Improve Attitude Measurements. Landsc. Urban Plan. 2005, 71, 147-162. [CrossRef]

32. Wan, C.; Shen, G.Q.; Choi, S. The Moderating Effect of Subjective Norm in Predicting Intention to Use Urban Green Spaces: A Study of Hong Kong. Sustain. Cities Soc. 2018, 37, 288-297. [CrossRef]

33. Altawallbeh, M.; Soon, F.; Thiam, W.; Alshourah, S. Mediating Role of Attitude, Subjective Norm And Perceived Behavioural Control In The Relationships Between Their Respective Salient Beliefs And Behavioural Intention To Adopt E-Learning Among Instructors In Jordanian Universities. J. Educ. Pract. 2015, 6, 152-159.

34. Chuang, L.-M.; Chen, P.-C.; Chen, Y.-Y. The Determinant Factors of Employees' Behavioral Intention in Green Building Restaurants-Integration TRA and TAM. Univers. J. Manag. 2016, 4, 704-713. [CrossRef]

35. Ignacio, J.J.; Malenab, R.A.; Pausta, C.M.; Beltran, A.; Belo, L.; Tanhueco, R.M.; Promentilla, M.A.; Orbecido, A. A Perception Study of an Integrated Water System Project in a Water Scarce Community in the Philippines. Water 2019, 11, 1593. [CrossRef]

36. Jahangir, N.; Begum, N. The Role of Perceived Usefulness, Perceived Ease of Use, Security and Privacy, and Customer Attitude to Engender Customer Adaptation in the Context of Electronic Banking. Afr. J. Bus. Manag. 2008, 2, 32-40. 
37. Hladnik, D.; Pirnat, J. Urban Forestry-Linking Naturalness and Amenity: The Case of Ljubljana, Slovenia. Urban For. Urban Green. 2011, 10, 105-112. [CrossRef]

38. Camacho-Cervantes, M.; Schondube, J.E.; Castillo, A.; MacGregor-Fors, I. How Do People Perceive Urban Trees? Assessing Likes and Dislikes in Relation to the Trees of a City. Urban Ecosyst. 2014, 17, 761-773. [CrossRef]

39. Coley, R.L.; Kuo, F.E.; Sullivan, W.C. Where Does Community Grow? The Social Context Created by Nature in Urban Public Housing. Environ. Behav. 1997, 29, 468-494. [CrossRef]

40. Giles-Corti, B.; Broomhall, M.H.; Knuiman, M.; Collins, C.; Douglas, K.; Ng, K.; Lange, A.; Donovan, R.J. Increasing Walking: How Important Is Distance to, Attractiveness, and Size of Public Open Space? Am. J. Prev. Med. 2005, 28, 169-176. [CrossRef] [PubMed]

41. Ostoić, S.K.; van den Bosch, C.C.K.; Vuletić, D.; Stevanov, M.; Živojinović, L.; Mutabdžija-Bećirović, S.; Lazarević, J.; Stojanova, B.; Blagojević, D.; Stojanovska, M.; et al. Citizens' Perception of and Satisfaction with Urban Forests and Green Space: Results from Selected Southeast European Cities. Urban For. Urban Green. 2017, 23, 93-103. [CrossRef]

42. Nesbitt, L.; Hotte, N.; Barron, S.; Cowan, J.; Sheppard, S.R. The Social and Economic Value of Cultural Ecosystem Services Provided by Urban Forests in North America: A Review and Suggestions for Future Research. Urban For. Urban Green. 2017, 25, 103-111. [CrossRef]

43. Coder, K.D. Trees and Humankind: Cultural and Psychological Bindings.; University of Georgia Cooperative Extension Service Forest Resources Unit: Athens, GA, USA, 1996.

44. Dwyer, J.F.; Nowak, D.J.; Watson, G.W. Future Directions for Urban Forestry Research in the United States. J. Arboric. 2002, 28, 231-236.

45. Lohr, V.I.; Pearson-Mims, C.H.; Tarnai, J.; Dillman, D.A. How Urban Residents Rate and Rank the Benefits and Problems Associated with Trees in Cities. J. Arboric. 2004, 30, 28-35.

46. Wan, C.; Shen, G.Q. Encouraging the Use of Urban Green Space: The Mediating Role of Attitude, Perceived Usefulness and Perceived Behavioural Control. Habitat Int. 2015, 50, 130-139. [CrossRef]

47. Zhang, Y.; Hussain, A.; Deng, J.; Letson, N. Public Attitudes toward Urban Trees and Supporting Urban Tree Programs. Environ. Behav. 2007, 39, 797-814. [CrossRef]

48. Public Works Department Taipei City Sidewalk Tree Information Website. Available online: https://geopkl.gov.taipei/ (accessed on 14 May 2021).

49. Neuman, W.L. Social Research Methods: Qualitative and Quantitative Approaches; Pearson Education Ltd.: Harlow, UK, 2013.

50. Department of Civil Affairs 2019-Statistics in Population and Each District Households. Available online: https:/ / english.ca.gov. taipei /News.aspx?n=0ED6677AC39FBAF0\&sms=6639445BA893E706. (accessed on 14 September 2020).

51. Hair, J.F.; Hult, G.T.M.; Ringle, C.M.; Sarstedt, M. A Primer on Partial Least Squares Structural Equation Modeling (PLS-SEM), 2nd ed.; Sage: Thousand Oaks, CA, USA, 2017.

52. Chin, H.C.; Choong, W.W.; Alwi, S.R.W.; Mohammed, A.H. Using Theory of Planned Behaviour to Explore Oil Palm Smallholder Planters' Intention to Supply Oil Palm Residues. J. Clean. Prod. 2016, 126, 428-439. [CrossRef]

53. Ringle, C.M.; Wende, S.; Becker, J.-M. SmartPLS 3. Available online: http:/ / www.smartpls.com (accessed on 1 July 2020).

54. Sarstedt, M.; Ringle, C.M.; Hair, J.F. Partial Least Squares Structural Equation Modeling. In Handbook of Market Research; Homburg, C., Klarmann, M., Vomberg, A., Eds.; Springer International Publishing: Cham, Switzerland, 2017; pp. 1-40. ISBN 978-3-319-05542-8.

55. Hulland, J. Use of Partial Least Squares in Strategic Management Research: A Review of Four Recent Studies. Strateg. Manag. J. 1999, 20, 195-204. [CrossRef]

56. Fornell, C.; Larcker, D.F. Evaluating Structural Equation Models with Unobservable Variables and Measurement Error. J. Mark. Res. 1981, 18, 39-50. [CrossRef]

57. Hair, J.F.; Ringle, C.M.; Sarstedt, M. Partial Least Squares: The Better Approach to Structural Equation Modeling? Long Range Plann. 2012, 45, 312-319. [CrossRef]

58. Chin, W.W. Issues and Opinion on Structural Equation Modeling. Manag. Inf. Syst. Q. 1998, 22, 7-16.

59. Cohen, J. Statistical Power Analysis for the Behavioral Sciences, 2nd ed.; Erlbaum: Hillsdale, NJ, USA, 1988.

60. Lin, J.C.; Chiou, C.R.; Chan, W.H.; Wu, M.S. Public Perception of Forest Ecosystem Services in Taiwan. J. For. Res. 2021, 1-8. [CrossRef]

61. Hair, J.F.; Ringle, C.M.; Sarstedt, M. PLS-SEM: Indeed a Silver Bullet. J. Mark. Theory Pract. 2011, 19, 139-152. [CrossRef]

62. Faul, F.; Erdfelder, E.; Lang, A.-G.; Buchner, A. G* Power 3: A Flexible Statistical Power Analysis Program for the Social, Behavioral, and Biomedical Sciences. Behav. Res. Methods 2007, 39, 175-191. [CrossRef]

63. Akter, S.; D'Ambra, J.; Ray, P. An Evaluation of PLS Based Complex Models: The Roles of Power Analysis, Predictive Relevance and GoF Index. In Proceedings of the Americas' Conference on Information Systems (AMCIS), Detroit, MI, USA, 4-8 August 2011.

64. Hair, J.F.; Ringle, C.M.; Sarstedt, M. Partial Least Squares Structural Equation Modeling: Rigorous Applications, Better Results and Higher Acceptance. Long Range Plan. 2013, 46, 1-12. [CrossRef]

65. Maichum, K.; Parichatnon, S.; Peng, K.-C. Application of the Extended Theory of Planned Behavior Model to Investigate Purchase Intention of Green Products among Thai Consumers. Sustainability 2016, 8, 1077. [CrossRef] 
66. Thompson, D.W.; Hansen, E.N. Carbon Storage on Non-Industrial Private Forestland: An Application of the Theory of Planned Behavior. Small-Scale For. 2013, 12, 631-657. [CrossRef]

67. Zhang, L.; Fan, Y.; Zhang, W.; Zhang, S. Extending the Theory of Planned Behavior to Explain the Effects of Cognitive Factors across Different Kinds of Green Products. Sustainability 2019, 11, 4222. [CrossRef]

68. Lo, A.Y.; Jim, C. Citizen Attitude and Expectation towards Greenspace Provision in Compact Urban Milieu. Land Use Policy 2012, 29, 577-586. [CrossRef]

69. Lam, K.-C.; Ng, S.-L.; Hui, W.-C.; Chan, P.-K. Environmental Quality of Urban Parks and Open Spaces in Hong Kong. Environ. Monit. Assess. 2005, 111, 55-73. [CrossRef]

70. Wicker, A. Attitudes versus Actions: The Relationship of Verbal and Overt Behavioural Responses to Attitude Objects. J. Soc. Issues 1969, 25, 41-78. [CrossRef]

71. Limayem, M.; Cheung, C.M. Predicting the Continued Use of Internet-Based Learning Technologies: The Role of Habit. Behav. Inf. Technol. 2011, 30, 91-99. [CrossRef] 